\title{
XIV \\ A EXPANSÃO DOS CURSOS DE GRADUAÇÃO A DISTÂNCIA NO OESTE DO PARANÁ*
}

Patrícia Cruz de Araújo

\section{INTRODUÇÃO}

Compreender como vem se configurando a ascensão da Educação a Distância no Oeste do Paraná, requer que, antes, seja feita uma análise de como ela foi sendo estabelecida no Brasil, ao longo da história, por meio de diversas políticas e ações que perpassam os governos. Contudo, não se pode deixar de considerar que um marco para a EaD no país foi a promulgação da vigente Lei de Diretrizes e Bases da Educação Nacional - LDBEN n 9.394/96, a qual veio para legitimá-la enquanto modalidade de educação, e, ainda hoje, serve como balizadora para diversos outros aportes legais com a finalidade de efetivá-la no cenário educacional brasileiro.

Convém pontuar a relevância em discutir essa temática, visto a crescente propagação da modalidade na região, especialmente no que diz respeito ao ensino superior privado, e, também, por identificar poucos estudos que tenham por premissa analisar a Educação a Distância no Oeste do Estado.

Nessa direção, o estudo inicia-se discorrendo sobre os desdobramentos da EaD e sua efetivação enquanto modalidade de educação no país, abordando-se sobre as políticas que foram sendo construídas com o passar dos governos, mas, principalmente, tratando-se dos aportes legais que servem de base para seu fortalecimento. Ainda, visando discorrer sobre a modalidade na mesorregião Oeste do Paraná, o estudo canalizou-se em analisar, individualmente, suas microrregiões: Cascavel, Foz do Iguaçu, e Toledo, trazendo questões como dados estatísticos sobre o ensino superior público e privado, e também sobre os cursos de graduação na modalidade presencial e a distância.

Por fim, apresenta o cenário dos cursos de graduação do sistema público e privado da região, na modalidade presencial e a distância, pontuando-se algumas IES, especialmente em se tratando das públicas que ofertam cursos de graduação EaD. Enfatiza-se que o estudo tem por base

*DOI - 10.29388/978-65-86678-77-2-0-f.192-206 
Referências bibliográficas, análises de documentos legais, informações disponibilizadas em páginas oficiais, e nos portais das instituições pesquisadas.

\section{A EAD E SUA EFETIVAÇÃO ENQUANTO MODALIDADE DE EDUCAÇÃO NO PAÍS}

Até se firmar enquanto modalidade de educação, a $\mathrm{EaD}$, tal qual hoje nos é posta, foi sendo construída ao longo dos anos em consonância com o desenvolvimento das chamadas NTICs - Novas Tecnologias de Informação e Comunicação (redes de comunicação interativas). Contudo, o fator central se encontra nas diferentes políticas que foram sendo construídas a cada governo de modo a consolidá-la no cenário educacional, destacando-se, por exemplo, a instituição de leis.

Em resumo, ao apresentar o quadro evolutivo da Educação a Distância, e, especialmente sobre as suas gerações, Pietrobon $(2018$, p. 25$)$ entende que há três momentos que se sobressaem, sendo:

O uso do correio primeiramente, com cursos de correspondência, os quais habilitavam muitas pessoas para um ofício; o suporte via rádio e televisão num segundo momento, por meio de programas educacionais a adultos para a conclusão de seus estudos na educação básica e, por fim, a internet como campo amplo para a divulgação de conhecimentos e com recursos diversos, tais como: sites de busca, ferramentas interativas, aplicativos, ambientes virtuais, redes sociais, entre outros. $\mathrm{Na}$ última geração da $\mathrm{EaD}$, quando já se tem a internet como propulsora dessa forma de educação, a modalidade em questão não ficou restrita a cursos voltados à aprendizagem de um ofício ou ao ensino secundário, mas ampliou-se em cursos de nível superior e de pós-graduação lato sensu.

Nessa vertente, sublinha-se que a efetivação da Educação a Distância, enquanto modalidade de educação, se deu a partir da promulgação da vigente Lei de Diretrizes e Bases da Educação Nacional - LDBEN n 9.394/96. Mais precisamente no seu art. 80, está disposto que "o Poder Público incentivará o desenvolvimento e a veiculação de programas de ensino a distância, em todos os níveis e modalidades de ensino, e de educação continuada" (BRASIL, 1996).

Ademais, legalmente fica definido como Educação a Distância, a partir do que está contido no art. $1^{\circ}$ do Decreto no 9.057, de 25 de maio de 2017, o qual regulamenta o art. 80 da Lei no 9.394, de 20 de dezembro de 1996, a 
[...] Modalidade educacional na qual a mediação didático-pedagógica nos processos de ensino e aprendizagem ocorra com a utilização de meios e tecnologias de informação e comunicação, com pessoal qualificado, com políticas de acesso, com acompanhamento e avaliação compatíveis, entre outros, e desenvolva atividades educativas por estudantes e profissionais da educação que estejam em lugares e tempos diversos (BRASIL, 2017).

Ainda analisando-se o ano de 1996, não se pode deixar de mencionar a criação da Secretaria de Educação a Distância - SEED, mediante o Decreto no 1.917, de 27 de maio, a qual veio para nortear ações em prol da consolidação da modalidade no país. A Secretaria foi extinta em 2011, onde suas atribuições foram repassadas para a Secretaria de Regulação e Supervisão da Educação Superior - SERES, fundada em 17 de abril de 2011 por meio do Decreto no 7.480/2011.

Evidencia-se que, a partir da LDBEN 9.394/96, foram se desdobrando diversos outros aportes legais visando a institucionalização da modalidade a distância. A título de exemplo, em 1998, o Decreto $\mathrm{n}^{\circ} 2.494$, de 10 de fevereiro, fora instituído para regulamentar seu art. 80, reiterando o que está nela disposto, porém, dando ainda mais credulidade para a atuação da iniciativa privada no quadro educacional, especialmente no tocante ao ensino superior. Nessa linha, o Decreto $n^{\circ} 5.622$ de 19 de dezembro de 2005, vem com a finalidade central de equiparar a validação dos cursos da modalidade a distância com os presenciais.

Diante do exposto, necessário se faz citar as instituições de ensino superior pioneiras no que se refere à oferta de Educação a Distância. No setor público, destaca-se a Universidade Federal de Santa Catarina (UFSC); a Universidade Federal de Pernambuco (UFPE); Universidade Federal de Minas Gerais (UFMG); Universidade Federal do Rio Grande do Sul (UFRGS); Universidade Federal de São Paulo (UNIFESP); e, no setor privado: Universidade Anhembi Morumbi (UAM); Pontifícia Universidade Católica de Campinas (PUC-Campinas); e o Centro Universitário Carioca (CUC).

Percebe-se que a modalidade veio ganhando expressiva propulsão, quando, em 2001, mediante a Portaria $n^{\circ} 2.253$, fica autorizada a oferta a distância de até $20 \%$ de disciplinas curriculares dos respectivos cursos presenciais das universidades, centros universitários, faculdades e centros tecnológicos. Além do mais, dá a abertura para que as universidades ou centros universitários alterem os projetos pedagógicos de cursos presenciais reconhecidos visando a oferta de disciplinas semipresenciais ou a distância. Nessa vertente, a Portaria do MEC no 4.059, de 10 de dezembro de 2004, veio para direcionar quanto à oferta de disciplinas na modalidade semipresencial 
em cursos de graduação presenciais. Após 15 anos, essas disposições tiveram mudanças com a Portaria $\mathrm{n}^{\circ}$ 2.117, de 6 de dezembro de 2019, a qual estabelece que as instituições de ensino superior podem ofertar até $40 \%$ da carga horária dos cursos presenciais de graduação por meio da Educação a Distância, não mais, até $20 \%$.

Nessa conjuntura, um grande feito para a entrada da EaD nas instituições públicas de ensino superior é o programa "Universidade Aberta do Brasil" (UAB), criado pelo Decreto no 5.800, de 8 de junho de 2006, tendo por objetivo maior a formação inicial e continuada de professores em exercício na educação básica da rede pública por meio da referida modalidade.

Ao se debruçar sobre a temática, Evangelista (2019) ressalta que até o ano de 2003, a Educação a Distância ainda não era vista como um nicho de mercado, posto que, até então, o setor público concentrava o maior número de matrículas. Contudo, entre 2003-2007, a autora intitula o que ela considera como "mercado das licenciaturas privadas", cenário esse em que o setor privado encontra nessa modalidade um mecanismo de lucro decorrente do seu alto potencial de custo-benefício.

Destaca-se que essa abertura para o sistema privado já está determinado na Constituição da República Federativa do Brasil de 1988, onde, em seu art. 209, estabelece que "o ensino é livre à iniciativa privada, atendidas as seguintes condições: I - cumprimento das normas gerais da educação nacional; II - autorização e avaliação de qualidade pelo Poder Público" (BRASIL, 1988).

Dessa forma, ao analisar a trajetória histórica da Educação a Distância, especialmente após o ano de 1996, fica evidente como ela vem tomando espaço no cenário educacional brasileiro e, ainda como maior intensidade, no ensino superior privado.

Como exemplos, cita-se o estudo realizado pela organização não governamental "Todos Pela Educação" (2019) a partir dos dados do Censo da Educação Superior 2017- Inep/MEC, em que constatou que $60 \%$ dos professores no Brasil são formados a distância, logo, de cada dez alunos de cursos de formação inicial de professores, seis estão em cursos ofertados na modalidade a distância. Além disso, reportando-se ao número de vagas oferecidas em cursos de graduação, por modalidade de ensino Brasil 20142018, o Censo da Educação Superior 2018 - Divulgação de resultados (2019) INEP/MEC, demonstra que: 


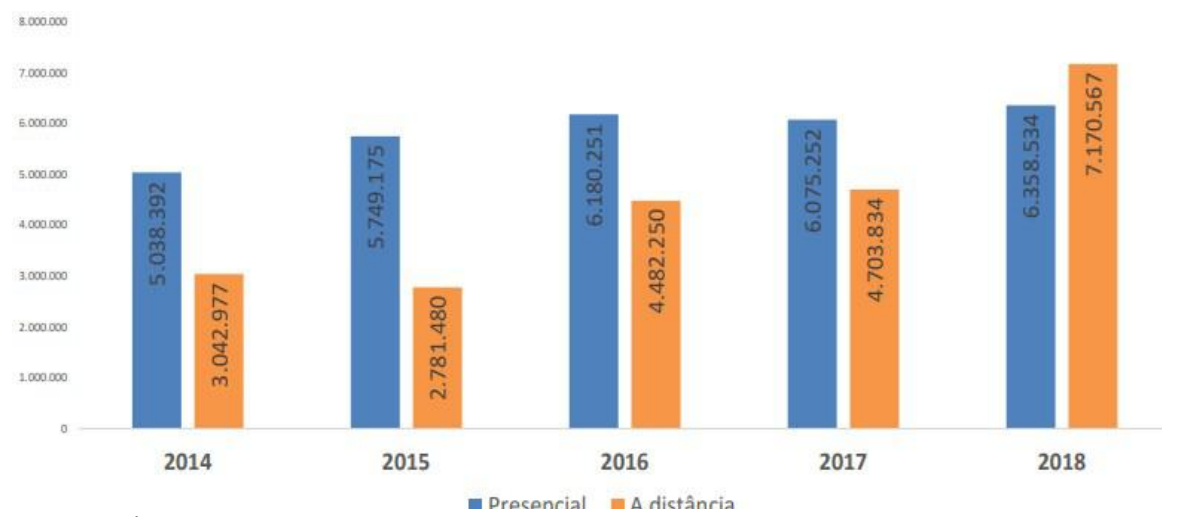

Fonte: MEC/Inep. Gráfico elaborado pelo Censo da Educação Superior 2018 - Divulgação de resultados (2019)

Ainda, de acordo com o INEP (2018), ao analisar os cursos de licenciatura no país, constatou que, pela primeira vez na história, o número de alunos nos cursos a distância foi maior do que nos cursos presenciais. Ou seja, $50,2 \%$, o equivalente à 816.888 dos licenciandos, estão em cursos a distância, enquanto 811.788 , o correspondente a $49,8 \%$, estão em cursos presenciais. Desse modo, permite-se observar como a modalidade vem se destacando no cenário brasileiro tendo por amparo bases legais e políticas voltadas para seu crescimento e supremacia, principalmente no setor privado.

Vale ainda mencionar que, mediante a Lei $\mathrm{n}^{\circ} 13.620$, de 15 de janeiro de 2018, fica determinado que no dia 27 de novembro comemora-se o Dia Nacional de Educação a Distância. Outro exemplo de ação direcionada para sua efetivação e vertiginosa expansão no território brasileiro.

\section{A REGIÃO OESTE DO PARANÁ: BREVES CONSIDERAÇÕES}

O Oeste Paranaense é composto por 50 municípios, com a população estimada em 1.315.226 habitantes (IPARDES, Instituto Brasileiro de Geografia e Estatística - IBGE, 2018). Quanto à constituição da região do Estado, Silva (2017, p. 52) disserta que:

A região oeste do Paraná é relativamente nova, se tomarmos como referência a história do Paraná e do Brasil. No entanto, apesar de ser de colonização recente, sua localização geográfica nas proximidades com a Argentina e com o Paraguai, e a facilidade de deslocamento para a região sul, para o sudeste e centro-oeste, bem como para a capital do Estado, tem facilitado o encontro e o convívio de culturas permitindo a realização de experiências bastante ricas e diversificadas. 
O mesorregião é dividida em três microrregiões, sendo elas, Cascavel, Foz do Iguaçu, e Toledo. No tocante à população, Cascavel tem estimada em 328.454 pessoas pelo Censo - 2019; Foz do Iguaçu, segundo levantamento do IBGE (2019), 258.532 habitantes; e o município de Toledo em 140.635 habitantes (IBGE, 2019).

Heringer (2017), realizou um estudo sobre as microrregiões do Oeste do Paraná, com recorte temporal de 2009-2012, e constatou, a começar pelo município de Cascavel, que o número de instituições de ensino superior privadas teve-se um aumento de $25 \%$, sendo que as públicas não obtiveram aumento. Ainda, no que diz respeito ao total de matrículas nos cursos de graduação tanto no setor público e privado, e também considerando as modalidades presencial e a distância, a região teve um aumento de $15,7 \%$. Se considerar, dentro desse quadro, somente a modalidade presencial, o estudo apontou que as matrículas nas IES privadas tiveram um acréscimo de $18,6 \%$ nesse período.

Em relação aos cursos de graduação na modalidade a distância nas IES públicas, a mesma apresentou decréscimo no total de matrículas, entorno de $75 \%$; enquanto as IES privadas tiveram acréscimo de $13,9 \%$. Em se tratando do município de Foz do Iguaçu, ao analisar o número de IES na microrregião nesse período, o autor constatou que não teve aumento no número de instituições privadas, porém, na categoria administrativa pública, teve-se o aumento mediante a implantação da universidade federal.

Ademais, no que se refere ao número de matrículas nos cursos de graduação, o estudo demonstra um aumento de $13,2 \%$, considerando as instituições públicas e privadas, e também as modalidades presencial e a distância. Na rede privada, considerando os cursos de graduação presenciais, teve-se um acréscimo de 4,3\% nas matrículas, e, nas públicas, um aumento de $51,3 \%$. O autor pontua que esse fato se deu por conta que, conforme descrito, o número de instituições privadas continuaram os mesmos, porém, no público teve-se a implantação de uma IES federal.

Ainda, levando-se em conta o total de matrículas nos cursos de graduação a distância, nas IES públicas, observou-se um decréscimo na ordem de $16,7 \%$, enquanto que nas privadas aumentou-se $11,5 \%$.

No município de Toledo, no tocante ao número de IES presentes na região no período analisado, evidenciou-se um aumento de $20 \%$ em relação às instituições privadas. Quanto ao número de matrículas nos cursos de graduação, o município apresentou um aumento de 5,4\%, contemplando, desse forma, tanto as instituições públicas e privadas, quanto em se tratando das modalidades presencial e a distância. 
Evidenciou-se, também, na modalidade presencial, um acréscimo de $14 \%$ no total de matrículas nas graduações das IES públicas. No que tange às IES pública federal, obteve-se um aumento nas matrículas o equivalente a $122,4 \%$, porém, nas IES públicas estaduais, o estudo constatou um decréscimo de $12,8 \%$.

Ainda, no que diz respeito ao total de matrículas dos cursos de graduação a distância, tanto das instituições públicas quanto privadas, constatou-se um decréscimo de 39,8\%, sendo relevante pontuar que, considerando somente os cursos de licenciatura na modalidade presencial, verificou-se um descréscimo de $28,2 \%$.

Segundo o material "Oeste do Paraná em números" (OBSERVATÓRIO TERRITORIAL, 2018), qual traz levantamentos estatísticos da região, em 2015, o Oeste, no que diz respeito ao número de estabelecimentos que ofertam cursos de graduação, no setor público, a região possui 10 estabelecimentos (foram consideradas todas as unidades das instituições de ensino públicas presentes na região), em contraste com os 35 privados (sendo que esses equivalem a $20,3 \%$ das faculdades do PR).

Para além, no que se refere ao número de programas de mestrado e doutorado, tendo como referência 2015, a região possui 34 de mestrado (o que equivale a $11 \%$ dos programas do Paraná), e 10 de doutorado ( $7 \%$ dos programas do Estado). Além disso, em relação ao número de mestres e doutores na região, possui 2.577 mestres (3,9\% dos Mestres do PR), e 1.347 doutores (9,2\% dos Doutores do PR).

Diante do exposto, fica aparente que, em âmbito geral, as instituições de ensino superior privadas vem crescendo e ampliando seu raio de atuação na região, acompanhando o movimento nacional, especialmente em relação à oferta de cursos de graduação a distância. Para além, isso evidencia que os intentos políticos em prol da hegemonia da formação superior privada e a distância, estão sendo, de fato, consolidadas.

\section{O CENÁRIO EXPANSIONISTA DOS CURSOS DE GRADUAÇÃO A DISTÂNCIA NO SISTEMA PÚBLICO E PRIVADO NA REGIÃO}

Para retratar o cenário expansionista dos cursos de graduação a distância no sistema público e privado na região, apresenta-se, separadamente, um panorama dos três municípios, Cascavel, Foz do Iguaçu e Toledo.

Desse modo, aborda-se sobre as suas instituições de ensino superior públicas e alguns exemplos de privadas, contemplando-se, também, um quadro dos cursos ofertados à distância por essas. Vale pontuar que, de modo 
geral, como cursos de graduação a distância considera-se, dentro das especificidades da modalidade, tanto os cursos semipresenciais quanto os chamados $100 \%$ online.

A começar por Cascavel, o município tem um Campus da Universidade Estadual do Oeste do Paraná - UNIOESTE. Por meio da Portaria Ministerial no 1051 de 09 de setembro de 2016, fica credenciado o Núcleo de Educação a Distância da Universidade Estadual do Oeste do Paraná - NEaDUNI. Tendo polos de apoio presencial distribuídos em diversos municípios do estado do Paraná, Rio Grande do Sul e Minas Gerais, de acordo com o Edital 05/2019, os cursos ofertados são: Letras Libras licenciatura (ofertado para 23 polos); Letras Libras bacharelado (ofertado para 13 polos), e Tecnologia em Gestão Pública (ofertado para 13 polos).

Cascavel também possui um campus do Instituto Federal do Paraná (IFPR). Além dos cursos presenciais, ofertam cursos na modalidade distância, tais como: Cursos Técnicos (Oferta 2019/2020), dispondo dos cursos de Administração, Agente Comunitário de Saúde, Logística, Meio Ambiente, Segurança do Trabalho, Serviços Públicos, e Vendas; e Curso Tecnológico (Oferta 2018/2020), oferecendo o curso de Segurança Pública.

No tocante às instituições privadas que ofertam cursos de graduação a distância no município, menciona-se, como exemplo, vinte instituições com considerável atuação na região: Faculdade Assis Gurgacz - FAG; UniCesumar; Universidade Paranaense - UNIPAR; Centro Universitário Internacional UNINTER; UNIVERSIDADE ESTÁCIO DE SÁ - UNESA; Universidade Paulista UNIP; Universidade do Norte do Paraná - UNOPAR; UNIVEL; Universidade Luterana do Brasil - ULBRA; Faculdade Educacional da Lapa - FAEL; Universidade Positivo; Universidade do Oeste Paulista - Unoeste; Universidade do Sul da Santa Catarina - UNISUL Virtual; Centro Universitário Campos de Andrade - Uniandrade; Uningá; UNITAU EAD; UNIASSELVI; Cruzeiro do Sul Virtual - Educação a Distância; Centro Universitário UNIFACVEST; SENAC EaD.

Algumas instituições, tais como, Faculdade Assis Gurgacz - FAG; Universidade Paranaense - UNIPAR, e UNIVEL ofertam cursos de graduação presencial e a distância, sendo que as duas primeiras ofertam mais cursos EaD do que presenciais.

Em Foz do Iguaçu, cita-se a Universidade Federal da Integração LatinoAmericana - UNILA, que possui um Núcleo de Educação a Distância - NEAD, estabelecido em 2015. A instituição não possui cursos de graduação EaD, porém, vale apontar que a mesma oferta cursos de extensão, como: Criação de material didático, Políticas Públicas e diversidade na escola, Preparación para la prueba de mestrado y doctorado en español, e Curso de Língua Guarani. 
O município também possui um Campus da Universidade Estadual do Oeste do Paraná - UNIOESTE. Sendo um polo de apoio presencial da Unioeste/NEaDUNI (Cascavel), oferta também dos seguintes cursos de graduação: Letras Libras Licenciatura, Letras Libras Bacharelado, Tecnologia em Gestão Pública e em curso de pós-graduação em Língua Inglesa para professores do Ensino Fundamental e Médio.

Além do mais, Foz do Iguaçu suporta um polo da Universidade Aberta do Brasil - UAB, nomeado de Polo universitário Darcy Ribeiro. Nesse ano, mediante parceria com a UNICENTRO, ofertam o curso de Licenciatura em Pedagogia, e em parceria com a UEM, Especialização em Atendimento Educacional Especializado, e Especialização em Educação Infantil.

Também possuem um Campus do Instituto Federal do Paraná - IFPR, na modalidade a distância, disponibilizam o curso Técnico em Administração, Técnico em Meio Ambiente, e Técnico em Segurança do Trabalho.

No que concerne às instituições privadas, cita-se: Universidade Paulista - UNIP; Universidade do Norte do Paraná - UNOPAR; UniCesumar; Faculdade Educacional da Lapa - FAEL; Universidade Anhanguera; Universidade do Oeste Paulista - Unoeste; Universidade Santo Amaro - UNISA; Centro Universitário Campos de Andrade - Uniandrade; UNIVERSIDADE ESTÁCIO DE SÁ - UNESA; Centro Universitário Internacional - UNINTER; União Dinâmica de Faculdades Cataratas - UDC; Cesufoz - Centro de Ensino Superior de Foz do Iguaçu; Faculdades Unificadas de Foz do Iguaçu - UNIFOZ; Cruzeiro do Sul Virtual Educação a Distância; Uniamérica - Campus CIBiogás - ITAIPU ; Centro Universitário Filadélfia - UniFil; Faculdade de Foz do Iguaçu - FAFIG; Centro Universitário UNIFACVEST; Faculdade de Educação São Luís - EaD Pleno; SENAC EaD. Dentre as vinte instituições listadas, cita-se a União Dinâmica de Faculdades Cataratas - UDC, a qual oferta mais cursos de graduação presenciais que a distância.

Como nos outros dois municípios, Toledo também possui um Campus da Universidade Estadual do Oeste do Paraná - UNIOESTE, contudo, não é um polo de apoio presencial da Unioeste/NEaDUNI (Cascavel), logo, ainda não oferta cursos na modalidade EaD.

Ademais, também tem um Campus da Universidade Tecnológica Federal do Paraná - UTFPR, a qual oferta cursos de pós-graduação lato sensu na modalidade EaD, contudo, não em Toledo, sendo exclusivamente nos Campus de Cornélio Procópio, Curitiba, Dois Vizinhos, Francisco Beltrão, e Medianeira. Além disso, tem um Campus da Universidade Federal do Paraná UFPR, entretanto, não oferta cursos na modalidade a distância.

Das instituições privadas que ofertam cursos de graduação a distância, destaca-se: Pontifícia Universidade Católica do Paraná - PUCPR; Universidade 
Paranaense - UNIPAR; Fundação Assis Gurgacz - FAG; FMU - Centro Universitário; Centro Universitário Internacional - UNINTER; Universidade Paulista - UNIP; Universidade do Norte do Paraná - UNOPAR; Faculdade Educacional da Lapa - FAEL; Universidade Positivo; FAM Online; Universidade Santo Amaro - UNISA; Centro Universitário Campos de Andrade - Uniandrade; Uningá; Cruzeiro do Sul Virtual - Educação a Distância; Uniamérica - BIOPARK; Campus UniBio/Prati-Donaduzzi; Centro Universitário Filadélfia - UniFil; Centro Universitário UNIFACVEST; Faculdade de Educação São Luís - EaD Pleno; SENAC EaD; Universidade Nove de Julho - UNINOVE. Entre essas, destaca-se a Pontifícia Universidade Católica do Paraná - PUCPR; Universidade Paranaense - UNIPAR; e a Fundação Assis Gurgacz - FAG, pois ofertam também cursos presencias, mas possuem maior número de cursos de graduação a distância.

Logo, ao analisar o quadro do ensino superior da região, evidencia-se uma expressiva atuação do setor privado e, em supremacia, no tocante à oferta de cursos de graduação a distância. Percebe-se também que muitas das IES privadas elencadas possuem polo de apoio presencial nas três microrregiões, o que demonstra, consequentemente, que possuem expressiva atuação na mesorregião.

\section{CONSIDERAÇÕES FINAIS}

O desenvolvimento da Educação a Distância no Brasil vem se configurando em consonância com a evolução tecnológica e informacional, todavia, é à luz de políticas delineadas ao longo dos anos nos diferentes governos que ela vem ganhando considerável e evidente expressividade, especialmente, a partir da promulgação da vigente Lei de Diretrizes e Bases da Educação Nacional - LDBEN $n^{\circ}$ 9.394/96, a qual instituiu a EaD como modalidade de educação.

Não de forma diferente, a mesorregião Oeste do Paraná vem de encontro a esse movimento. Sendo dividido em três microrregiões: Cascavel, Foz do Iguaçu e Toledo, apresenta um considerável número de instituições de ensino superior públicas, porém, um número ainda mais notório no que tange às instituições privadas. Ressalta-se que, grande parte dessas, ofertam cursos de graduação a distância.

Cabe, ainda, considerar que a maioria dessas instituições privadas ofertam cursos de Pedagogia na modalidade presencial e/ou a distância, logo, pensando em relação à formação inicial de professores, certamente a região conta com grande parte de seus professores formados no setor privado.

Assim sendo, pontua-se a relevância em discutir a temática proposta, mas também a necessidade de se somar outros estudos que tenham por 
intento compreender e demonstrar como vem sendo configurado esse cenário expansionista do setor privado na região. A questão central não está em polarizar ensino presencial e a distância, público e privado, mas em demonstrar de que forma o ensino superior está estruturado na região, analisando quais são os reais intentos políticos e legais, e, por fim maior, identificar suas decorrentes consequências para o presente e o futuro da sociedade como um todo.

\section{REFERÊNCIAS}

BRASIL. Censo da Educação Superior 2018: Divulgação dos resultados. MEC/INEP, 2019. Disponível em: http://download.inep.gov.br/educacao_superior/censo_superior/documentos /2019/apresentacao_censo_superior2018.pdf. Acesso em: 09 mai. 2020.

BRASIL. Constituição da República Federativa do Brasil de 1988. Brasília, DF: Presidência da República, [1988]. Disponível em: http://www.planalto.gov.br/ccivil_03/constituicao/constituicao.htm. Acesso em: 9 mai. 2020.

BRASIL. Presidência da República. Casa Civil. Subchefia para Assuntos Jurídicos. Decreto ${ }^{\circ} \mathbf{2} .494$ de 10 de fevereiro de 1998. Regulamenta o Art. 80 da LDB (Lei n.o 9.394/96). Brasília, DF: Presidência da República, 1998. Disponível em: http://portal.mec.gov.br/seed/arquivos/pdf/tvescola/leis/D2494.pdf. Acesso em: 13 mar. 2020.

BRASIL. Lei n.o 9.394, de 20 de dezembro de 1996. Estabelece as diretrizes e bases da educação nacional. Diário Oficial da República Federativa do Brasil, Brasília, DF, 23 dez. 1996.

BRASIL. Ministério da Educação. Portaria $n^{\circ}$ 2.253, de 18 de outubro de 2001. Dispõe sobre a introdução nas instituições de ensino superior do sistema federal de ensino, na organização pedagógica e curricular de seus cursos superiores reconhecidos, a oferta de disciplinas que, em seu todo ou em parte, utilizem método não presencial, com base no art. 81 da Lei n. 9394, de 1996. Brasília, DF: Ministério da Educação, 2001. Disponível em:

https://www2.camara.leg.br/legin/marg/portar/2001/portaria-2253-18outubro-2001-412758-norma-me.html. Acesso em: 08 mai. 2020.

BRASIL. Ministério da Educação. Portaria no 4.059, de 10 de dezembro de 2004. Dispõem que as instituições de ensino superior poderão introduzir, na organização pedagógica e curricular de seus cursos superiores reconhecidos, a oferta de disciplinas integrantes do currículo que utilizem modalidade 
semipresencial, com base no art. 81 da Lei n. 9.394, de 1.996, e no disposto nesta Portaria. Brasília, DF: Ministério da Educação, 2004. Disponível em: http://portal.mec.gov.br/sesu/arquivos/pdf/nova/acs_portaria4059.pdf. Acesso em: 13 mai. 2020.

BRASIL. Presidência da República. Casa Civil. Subchefia para Assuntos Jurídicos. Decreto Federal no 5.622, de 19 de dezembro de 2005. Regulamenta o art. 80 da Lei no9.394, de 20 de dezembro de 1996, que estabelece as diretrizes e bases da educação nacional. Brasília, DF: Presidência da República, 2005. Disponível em:

https://abmes.org.br/arquivos/legislacoes/Dec_5622_191205.pdf. Acesso em: 08 mai. 2020.

BRASIL. Presidência da República. Casa Civil. Subchefia para Assuntos Jurídicos. Decreto no 5.800, de 8 de junho de 2006. Dispõe sobre o Sistema Universidade Aberta do Brasil - UAB. Brasília, DF: Presidência da República, 2006.

Disponível em:

http://www.planalto.gov.br/ccivil_03/_Ato2004-2006/2006/Decreto/D5800.ht m. Acesso em: 20 abr. 2020.

BRASIL. Presidência da República. Casa Civil. Subchefia para Assuntos Jurídicos. Decreto no 9.057, de 25 de maio de 2017. Regulamenta o art. 80 da Lei $n$ - 9.394, de 20 de dezembro de 1996, que estabelece as diretrizes e bases da educação nacional. Brasília, DF: Presidência da República, 2017. Disponível em:

http://www.planalto.gov.br/ccivil_03/_Ato2015-2018/2017/Decreto/D9057.ht m\#art24. Acesso em: 12 mai. 2020.

BRASIL. Lei no 13.620, de 15 de janeiro de 2018. Institui o dia 27 de novembro como Dia Nacional de Educação a Distância. Brasília, DF: Presidência da República, [2018]. Disponível em:

http://www.planalto.gov.br/ccivil_03/_ato2015-2018/2018/lei/L13620.htm. Acesso em: 22 abr. 2020.

BRASIL. Ministério da Educação. Portaria no 2.117, de 6 de dezembro de 2019. Dispõe sobre a oferta de carga horária na modalidade de Ensino a Distância - EaD em cursos de graduação presenciais ofertados por Instituições de Educação Superior - IES pertencentes ao Sistema Federal de Ensino. Brasília, DF: Ministério da Educação, 2019. Disponível em: http://www.in.gov.br/en/web/dou/-/portaria-n-2.117-de-6-de-dezembro-de2019-232670913. Acesso em: 12 mai. 2020. 
EVANGELISTA, O. A formação de professores no contexto atual. Fortaleza, 2019. 16 slides.

HERINGER, Eudiman. A expansão da educação superior na região Oeste do Paraná e suas influências no grau de formação dos professores universitários. 2017. Dissertação (Mestrado em Educação) - Programa de Pós-Graduação Strictu Sensu em Educação - PPGE, Universidade Estadual do Oeste do Paraná, Cascavel, 2017. Disponível em:

http://tede.unioeste.br/bitstream/tede/3334/5/Eudiman_Heringer2017.pdf. Acesso em: 13 mai. 2020.

IFPR. Educação a Distância. Disponível em: https://ead.ifpr.edu.br/. Acesso em: 13 mai. 2020.

INSTITUIÇÕES DE ENSINO SUPERIOR PRIVADAS EM CASCAVEL - PARANÁ. In: Google Disponível em: https://www.google.com/search?

$\mathrm{rlz}=1$ 1C1GCEA_enBR859BR859\&sxsrf=ALeKk00UM26DieLAK7Rq2haGvpOPFnGw Q\%3A1589412516358\&ei=plK8XsWuFfjG5OUPsvy9wAc\&q=Institui $\%$ C3\%A7\%C3\%B5es+de+ensino+superior+privadas+em+cascavel+ \%E2\%80\%93+Paran\%C3\%A1\&oq=Institui

$\% \mathrm{C} 3 \% \mathrm{~A} 7 \% \mathrm{C} 3 \% \mathrm{~B} 5 \mathrm{es}+\mathrm{de}+$ ensino+superior+privadas+em+cascavel+ \%E2\%80\%93+Paran

\%C3\%A1\&gs_Icp=CgZwc3ktYWIQAzoECAAQRzoECCMQJzoECAAQQzoFCAAQgw E6AggAOgcllxDqAhAnOgQIIRAKUKHBlirvQdgxb4HaAJwAXgCgAG3BogB3EySAQ syLTluNi4zLjcuMpgBAKABAaABAqoBB2d3cy13aXqwAQo\&sclient=psyab\&ved=0ahUKEwjFkMGD_7HpAhV4I7kGHTJ-D3gQ4dUDCAw\&uact=5. Acesso em: 10 mai. 2020.

INSTITUIÇÕES DE ENSINO SUPERIOR PRIVADAS EM FOZ DO IGUAÇU - PARANÁ. In: Google. Disponível em: https://www.google.com/search?q=Institui \%C3\%A7\%C3\%B5es+de+ensino+superior+privadas+em+Foz+do+lgua \%C3\%A7u+\%E2\%80\%93+Paran \%C3\%A1\&rlz=1C1GCEA_enBR859BR859\&oq=Institui $\% \mathrm{C} 3 \% \mathrm{~A} 7 \% \mathrm{C} 3 \% \mathrm{~B} 5$ es+de+ensino+superior+privadas+em+Foz+do+lgua \%C3\%A7u+\%E2\%80\%93+Paran \%C3\%A1\&aqs=chrome..69i57.484j0j7\&sourceid=chrome\&ie=UTF-8. Acesso em: 10 mai. 2020.

INSTITUIÇÕES DE ENSINO SUPERIOR PRIVADAS EM TOLEDO - PARANÁ. Google. Disponível em: https://www.google.com/search? $\mathrm{rlz}=1$ C1GCEA_enBR859BR859\&sxsrf=ALeKk01oanojwB1FhWi3P0Tu50fNZbg4w \%3A1589412513218\&ei=oYK8XoLtDMGn5OUPj9Cy8Ag\&q=INSTITUI $\% C 3 \% 87 \%$ C3\%95ES+DE+ENSINO+SUPERIOR+privadas+EM+toledo+pARANA\&o 
$\mathrm{q}=|\mathrm{NSTITU}|$

$\% C 3 \% 87 \% C 3 \% 95 E S+D E+E N S I N O+S U P E R I O R+p r i v a d a s+E M+t o l e d o+p A R A N A \& g s$ _lcp=CgZwc3ktYWIQAzIFCCEQoAEyBQghEKABOgQIABBHOgQIIxAnUPkGWMM MYKEOaABwAXgAgAGZBIgBggiSAQcyLTluNSOxmAEAoAEBqgEHZ3dzLXdpeg\&scl ient=psy-

ab\&ved=0ahUKEwjCwYGC_7HpAhXBE7kGHQoDI4Q4dUDCAw\&uact=5. Acesso em: 10 mai. 2020.

IPARDES. Perfil avançado do município de Toledo. Disponível em:

http://www.ipardes.gov.br/perfil_municipal/MontaPerfil.php?

codlocal=184\&btOk=ok. Acesso em: 13 mai. 2020.

OBSERVATÓRIO TERRITORIAL. Oeste do Paraná em números. Foz do Iguaçu, 2018. Disponível em:

https://www.oesteemdesenvolvimento.com.br/src/pagina_arquivo/15.pdf. Acesso em: 12 mai. 2020.

PIETROBON, Sandra Regina Gardacho. A formação do professor da educação infantil no contexto da modalidade a distância: o curso de Pedagogia em foco. 2018. Tese (Doutorado em Ensino de Ciência e Tecnologia) - Programa de PósGraduação em Ensino de Ciência e Tecnologia, Universidade Tecnológica Federal do Paraná, Ponta Grossa, 2018. Disponível em:

http://repositorio.utfpr.edu.br/jspui/bitstream/1/3350/1/PG_PPGECT_D_Pietr obon\%2C\%20Sandra\%20Regina\%20Gardacho_2018.pdf. Acesso em: 12 mai. 2020.

SILVA. J. C. História e historiografia da educação na Região Oeste do Paraná: alguns apontamentos. Revista Humanidades. Fortaleza, v. 32, n. 1, p. 47-57, jan./jun. 2017. Disponível em: file:///E:/Arquivos/Downloads/6804-24382-1SM.pdf. Acesso em: 12 mai. 2020.

TODOS PELA EDUCAÇÃO. Com qualidade inferior, número de ingressantes na formação de professores a distância dobra nos últimos sete anos., 15 ago 2019. Disponível em: https://www.todospelaeducacao.org.br/conteudo/Comqualidade-inferior_-numero-de-ingressantes-na-formacao-de-professores-adistancia-dobra-nos-ultimos-sete-anos. Acesso em: 11 mai. 2020.

UAB. Polo universitário Darcy Ribeiro. Disponível em: https://uab.pti.org.br/. Acesso em: 12 mai. 2020.

UFPR. Cursos a distância. Disponível em:

https://www.ufpr.br/portalufpr/cursos-a-distancia/. Acesso em: 12 mai. 2020.

UNILA. Núcleo de Educação a Distância - NEAD. Disponível em: https://portal.unila.edu.br/nead. Acesso em: 12 mai. 2020. 
UNIOESTE. Núcleo de Educação a Distância da Universidade Estadual do Oeste do Paraná - NEaDUNI. Disponível em:

https://www5.unioeste.br/portalunioeste/nucleos/neaduni/neaduni. Acesso em: 12 mai. 2020.

UTFPR. Educação a Distância. Disponível em:

http://portal.utfpr.edu.br/cursos/educacao-a-distancia. Acesso em: 12 mai. 2020. 